\title{
Correction to: Core Competencies in VA Compensation and Pension Exams for PTSD and Other Mental Disorders
}

\author{
Thor Johansen ${ }^{1}$ (C)
}

Published online: 24 October 2017

(C) Springer Science+Business Media, LLC 2017 Correction to: Psychol. Inj. and Law (2017) 10(3):234-243
https://doi.org/10.1007/s12207-017-9298-2

Correction of mistake in the original version of this paper, "Core Competencies in VA Compensation and Pension Exams for PTSD and Other Mental Disorders", the sentence "Other recommended aspects of this axis include familiarity with the VA's Best Practice Manual for Posttraumatic Stress Disorder Compensation and Pension Examinations (Watson, McFall, McBrine, Schnurr, Friedman, Keane, \& Hamblen, 2002), familiarity with the Specialty Guidelines for Forensic Psychology (American Psychiatric Association, 2013), and continued professional development through familiarity with the professional literature as it relates to VA C\&P examinations and professional consultation." should read "Other recommended aspects of this axis include familiarity with the VA's Best Practice Manual for Posttraumatic Stress Disorder
Compensation and Pension Examinations (Watson, McFall, McBrine, Schnurr, Friedman, Keane, \& Hamblen, 2002), familiarity with the Specialty Guidelines for Forensic Psychology (American Psychological Association, 2013), and continued professional development through familiarity with the professional literature as it relates to VA C\&P examinations and professional consultation."

The sentence "Additionally, given the forensic nature of C\&P evaluations, examiners should be familiar with the basic principles of forensic psychology outlined in the Specialty Guidelines for Forensic Psychology (American Psychiatric Association, 2013)." should read "Additionally, given the forensic nature of C\&P evaluations, examiners should be familiar with the basic principles of forensic psychology outlined in the Specialty Guidelines for Forensic Psychology (American Psychological Association, 2013).”

The online version of the original article can be found at https://doi.org/ 10.1007/s12207-017-9298-2

Thor Johansen

Tj902@live.com

1 Northern Arizona VA Health Care System, Prescott, AZ, USA 